\title{
Application of AHP for the Criteria Evaluation of a Public Procurement in Colombia
}

\author{
[Jose, Laura, Eugenio, Jose]
}

\begin{abstract}
In order to conduct a verification of the methodologies used by the Ministry of Education of Colombia in the selection of contractors, a process of selection of bidders through Analytic Hierarchy Process (AHP) was replicated. From the theoretical development of AHP as a tool for decision making, this paper presents the application of the method in public procurement through a case study in which the similarities and differences were compared with the actual outcome of the process. Among the main characteristics generally found that the classification given by the traditional process has a level of identity of $67 \%$ compared to the result obtained by the application of AHP. In addition to this, we found that at the point of no coincidence between process and AHP, the contractor had lower levels of performance compared to other contractors. These results are the base to initiate a search for new methods and selection criteria of proponents focusing on getting the contractor that better meet the objectives required for the construction of public infrastructure.
\end{abstract}

Keywords - AHP, public procurement, decision making, recruitment process, contractor.

\section{Introduction}

Decision making study investigates the behavior of decision makers and the conditions that may affect decisions (Vallejo-Borda, Ponz-Tienda \& Alzate-Alzate 2014). From this principle, researchers over the years have focused on this area in order to generate tools that facilitate decision making in various aspects or contexts. Usually, in the decision making process, several criteria are used to rate the alternatives. The tools, and process that contemplate these criteria are called Multi-criteria Decision Making (MCDM).

Jose Agustin Vallejo Borda (Author)

Universidad de los Andes

Colombia

Laura Andrea Gutierrez Bucheli (Author)

Universidad de los Andes

Colombia

Eugenio Pellicer (Author)

Universidad Politécnica de Valencia

Spain

Jose Luis Ponz-Tienda (Author)

Universidad de los Andes

Colombia
There are two types of classifications for MCDM. The first one takes the categorization from Multiple Objective Decision Making (MODM) and the second from Multi-attribute Decision Making (MADM). The MODM classification includes methodologies such as Multi-attribute Utility Theory (MAUT), Elimination and Choice Translating Reality (ELECTRE) and the Analytic Hierarchy Process (AHP), which take into account some constraints in the evaluation of the alternatives (Herath 2010). These methodologies in turn are quantitative and do not take the risk into account.

Among the methodologies used to study decision problems with multiple objectives is AHP, whose most important aspect is the power to decrease the manipulation of the information. In other words, the AHP provides a shield of transparency in the decision to reduce subjectivity in the process of decision making (Casañ Perez, Ponz Tienda, \& Bustos Chocomeli 2013).

On the other hand, Colombia has been a country whose history does not generate tranquility for current generations due to the perceived lack of transparency in most decisions in the country. This point is of paramount importance because the country needs to progress, and the sense of nontransparency in decisions will generate a contrary result.

In the Colombian context, the application of the AHP could be beneficial for the country's development. For this reason, it is important to know how Colombian entities developed the different processes to select contractors and to teach about MCDM methods. However, the application of MCDM methods in state processes worldwide is negligible due to the lack of information on the methodology and the applicability of its results (Vallejo-Borda, Ponz-Tienda \& Alzate-Alzate 2014).

\section{State of the art}

Thomas Saaty (1979) published a document addressed to the office of the United States Air Force, which explained how the AHP could enhance the desired results from decision making. After this work, started in the 1970s, the following years saw continuous research and application of the AHP in different aspects of life.

Governments began to take an interest in the use or application of AHP to make decisions objectively using a novel mathematical tool. For this reason, in the 1990s, in Europe there was research based on the AHP for selecting the places where transport terminals should be located. Through the AHP (considering aspects of costs, risks, accessibility and incentives), it was possible to determine the best geographical location of terminals, considering multiple objectives that in several cases had been in conflict with each other (Min 1994). 
In later years, the research on the AHP expanded its vision to address other viable options for government use. Some examples were the use of the AHP for evaluating the priority of highway construction in Japan (Ando 2004), analysis of risks of collapse in sinks and generally in mining (Jiang, Lei, $\mathrm{Li}$, \& Dai 2005 ) and economic analysis aimed at determining the best value generator projects (Abdelrahman, Zayed, \& Elyamany 2008), which is a priority for governments.

From these applications, the research around the AHP in government use was increasing as the years passed. In later years, the AHP was used to measure the risks involved in the management of urban infrastructure projects (Chen \& Qin 2009), as well as to assess the logistical development of different regions in China (Qin 2010).

The use of the AHP by governments also took place in the area of sustainable development of society and environment care. Proof of this was the use of the AHP to determine the location of furniture for parks in different parks of China (Chen, Yang, \& Xu 2012), or the use of AHP aimed at achieving sustainable social development through the identification of processes that facilitate the social integration of works in the planning and design stages (Valdes Vasquez \& Klotz 2013).

Governments around the world have prioritized the management of risks and responses of their emergency equipment against possible disasters. For this reason, the AHP was used as a selection tool of fortress for use after earthquakes (Cheng \& Yang 2012), as well as to measure the psychological capacity in the operation of rescue equipment (Xue \& Liu 2014). Continuing in the field of risk, the AHP has been used as a powerful tool for warning of vehicle emergencies, seeking to eliminate misinformation in warning systems present on motorways (Xue, Zhang, \& Yang 2014).

Currently, infrastructure development is of vital importance to the economic development of countries. That is why, through the AHP, countries like China have conducted a careful analysis using the AHP that focused on identifying the features needed to verify the quality of products obtained through Private Public Partnership (PPP) social housing (Yuan, Guang, Wang, Li, \& Skibniewski 2012). Likewise, the AHP has been used as a tool to prioritize measures to improve the conditions of highways in areas with very limited resources (Chen \& Hsu 2014). These factors and interests in infrastructure show the need to expand knowledge in the development of infrastructure contracts in order to be able to ensure their success.

\section{Methodology and Data Collection}

To carry out this research, it was necessary to divide the process into two main stages. The first aims to get the necessary data from the recruitment process, while the second stage conducts the analysis of these data through the AHP.

The data collection is the basis for the development of this research that involves a procurement process developed by the Ministry of National Education of Colombia in the form of
Merit Competition. Because the required information is public sector, all the data and information necessary for this research is available in "Portal Único de Contratación Colombia Compra (SECOP)". The SECOP provides information in general for the recruitment process in the form of Merit Competition, as follows:

- $\quad$ Draft Process

- Call Process

- Technical Assessment Reports, Legal and Financial proponents

- Termination Act

- Adjudication Act

- $\quad$ Act of Settlement

Through these stages, it will be possible to obtain the information necessary for the proper conduct of this investigation. This information is based on finding the qualifying requirements of the selected process as a case study. In a similar vein, the reports made on the scoring and award of the proponent's ratings were accessed through SECOP.

\section{Iv. The application of the AHP}

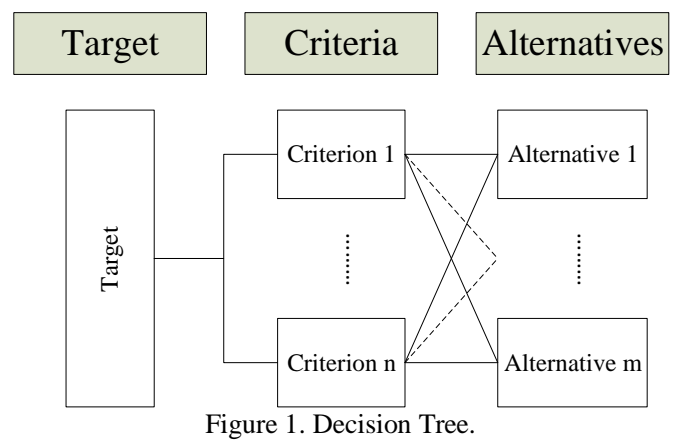

In general, the AHP is a tool to select, from a group of alternatives, the one that best meets the objective. Furthermore, this process can be divided into four steps: 1) Structuring the problem, 2) Qualitative Analysis, 3) Quantitative Analysis and 4) Analysis of results. In developing the first step, it is essential to identify the main purpose to fulfill. For this, it is necessary to define the fragmentation problem or important criteria so as to decide the sub-criteria. Also, by means of decision trees it is possible to correctly illustrate the result of this stage (Fig. 1).

For the second step, it is necessary to build, through matrices, comparisons of importance among criteria and preferences among alternatives. For this construction and in those cases where data are available, it is possible to assemble the matrices by means of the relationship between $\mathrm{w}$ values of the criteria or the alternatives according to the evaluation being conducted in order to find the matrix $A$ pairwise comparison (1). 


$$
A=\left[\begin{array}{cccc}
\frac{w_{1}}{w_{1}} & \frac{w_{1}}{w_{2}} & \cdots & \frac{w_{1}}{w_{n}} \\
\frac{w_{2}}{w_{2}} & \frac{w_{2}}{w_{1}} & \ldots & \frac{w_{2}}{w_{2}} \\
\vdots & \vdots & \cdots & \frac{w_{n}}{w_{n}} \\
\frac{w_{n}}{w_{n}} & \frac{w_{n}}{w_{n}} & \cdots & \frac{1 w_{n}}{w}
\end{array}\right]
$$

The third step is a quantitative analysis of the matrix $A$ built in the previous step. Through this analysis, the process seeks to know the relative importance of the criteria or alternatives regarding the superior criterion with the objective of sorting the different options, which is achieved when it finds the maximum eigenvalue $\lambda$ of the matrix $A$ and calculates the associated eigenvector $W(2)$.

$$
A * W=\lambda_{\max } * W
$$

Through eigenvector $\mathrm{W}$, it is possible to find $\widehat{W}$, which corresponds to the normalized eigenvector as appropriate, so that the represented weights sum to 1 .

For the successful application of the AHP, it is necessary to perform a consistency check using the maximum eigenvalue and the matrix size (n) of $A$. In order to measure the consistency there are two indicators; the first is the consistency index (CI) of the matrix $A$ and the second is the consistency ratio of the matrix $A(\mathrm{CR})$. The CI (3) to measure the coherence between the relations given in the construction of the matrix $A$, that is, when the matrix is assembled from data, must be equal or very close to 0 . Similarly, CR (4) indicates the overall consistency of the process. To be considered acceptable results, the RC should be less than $10 \%$ and its approach to 0 indicates perfect consistency of the process.

$$
\begin{gathered}
C I=\frac{\lambda_{\max }-n}{n-1} \\
C R=\frac{C I}{R I}, R I \cong \frac{1,9 g *(n-2)}{n}
\end{gathered}
$$

The fourth and final step is to conduct the respective analysis of the results obtained by performing the above steps. This analysis should contain a respective recommendation in accordance with the variables found in the model.

\section{v. Case Study and Results of Application}

The case study will focus on the competitive examination with process contract number CM-MEN-04-2013, which has an official budget of $\$ 1,616,267,599$. From this process, three contracts were awarded for the design as shown in Table 1.

These contracts were awarded through the evaluation criteria and sub-criteria; these were adequate for the contracting entity to achieve its main objective. These criteria are shown in Fig. 2.

TABLE I. CONTRACT AWARD PROCESS CM-MEN-04-2013

\begin{tabular}{|c|c|c|}
\hline Contract & Budget & Contractor \\
\hline "678 de $2013 "$ & $\$ 519,775,816$ & CONSUCON LIMITADA \\
\hline "679 de 2013" & $\$ 551,153,366$ & EDICO SAS \\
\hline "680 de 2013" & $\$ 545,155,920$ & $\begin{array}{c}\text { CONSORCIO } \\
\text { INFRAESTRUCTURA }\end{array}$ \\
\hline
\end{tabular}

From Fig. 2 and by means of the scores established in the hiring process, the weights set for all the criteria were calculated. These weights are shown in Table 2. 
Proc. of the Third Intl. Conf. Advances in Civil, Structural and Mechanical Engineering- CSM 2015

Copyright (C) Institute of Research Engineers and Doctors, USA .All rights reserved.

ISBN: 978-1-63248-062-0 doi: 10.15224/ 978-1-63248-062-0-67

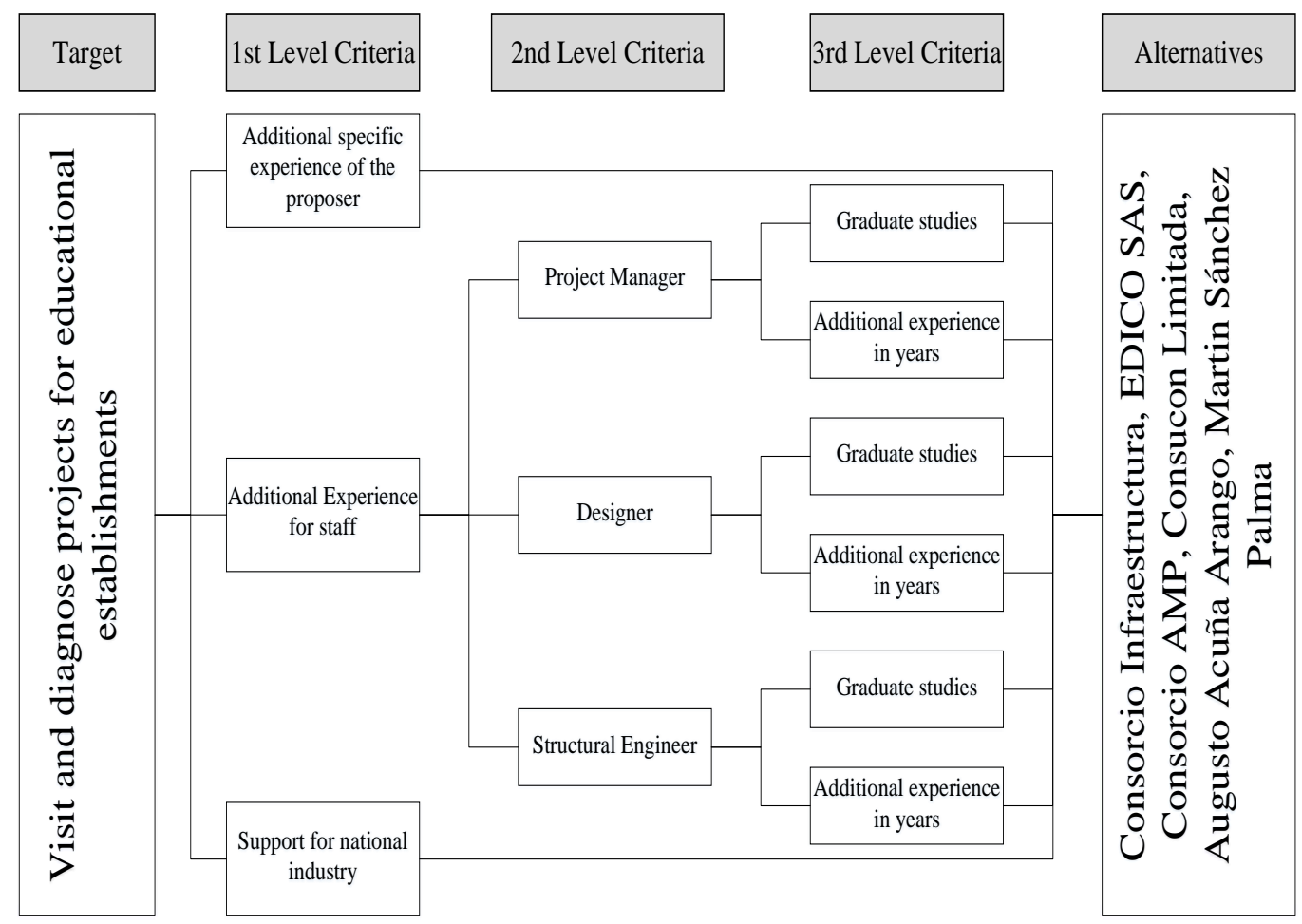

Figure 2. Decision tree process CM-MEN-04-2013

Through the distribution of the weights of the criteria in Table 2 and through the actual data that were taken into account in the selection of the proponents in the hiring process (Table 3), it is possible to start the analysis through the AHP.
Similarly, in developing the research, additional data were found that were not taken into account in the scoring process but were requested as qualifying requirements (Table 4).

TABLE II. WEIGHT OF FIRST, SECOND AND THIRD LEVEL

\begin{tabular}{|c|c|c|c|c|c|c|c|c|}
\hline \multicolumn{2}{|r|}{ First Level Criteria } & \multirow{2}{*}{\begin{tabular}{|c|} 
Weight \\
0.50
\end{tabular}} & \multicolumn{2}{|c|}{ Second Level Criteria } & \multirow[t]{2}{*}{ Weight } & \multicolumn{2}{|r|}{ Third Level Criteria } & \multirow[t]{2}{*}{ Weight } \\
\hline 1 & $\begin{array}{l}\text { Additional specific experience of } \\
\text { the proposer }\end{array}$ & & & & & & & \\
\hline \multirow{6}{*}{2} & \multirow{6}{*}{ Additional experience for staff } & \multirow{6}{*}{0.40} & \multirow[b]{2}{*}{2.1} & \multirow[b]{2}{*}{ Project Manager } & \multirow[b]{2}{*}{0.50} & 2.1.1 & Graduate Studies & 0.50 \\
\hline & & & & & & 2.1 .2 & \begin{tabular}{|l|}
$\begin{array}{l}\text { Additional Experience in } \\
\text { years }\end{array}$ \\
\end{tabular} & 0.50 \\
\hline & & & \multirow[b]{2}{*}{2.2} & \multirow[b]{2}{*}{ Designer } & \multirow[b]{2}{*}{0.25} & 2.2 .1 & Graduate Studies & 0.40 \\
\hline & & & & & & 2.2 .2 & $\begin{array}{l}\begin{array}{l}\text { Additional Experience in } \\
\text { years }\end{array} \\
\end{array}$ & 0.60 \\
\hline & & & \multirow[b]{2}{*}{2.3} & \multirow[b]{2}{*}{ Structural Engineer } & \multirow[b]{2}{*}{0.25} & 2.3 .1 & Graduate Studies & 0.40 \\
\hline & & & & & & 2.3 .2 & \begin{tabular}{|l|}
$\begin{array}{l}\text { Additional Experience in } \\
\text { years }\end{array}$ \\
\end{tabular} & 0.60 \\
\hline 3 & Support for national industry & 0.10 & & & & & & \\
\hline
\end{tabular}


Proc. of the Third Intl. Conf. Advances in Civil, Structural and Mechanical Engineering- CSM 2015

Copyright (C) Institute of Research Engineers and Doctors, USA .All rights reserved.

ISBN: 978-1-63248-062-0 doi: 10.15224/ 978-1-63248-062-0-67

TABLE III. QUALIFYING INFORMATION ON PROPONENT'S PROCESS CM-MEN-04-2013

\begin{tabular}{|c|c|c|c|c|c|c|c|c|}
\hline \multirow{2}{*}{ CONTRACTOR } & \multicolumn{9}{|c|}{\begin{tabular}{c} 
QUALIFYING \\
\cline { 2 - 9 }
\end{tabular}} & $\begin{array}{c}\text { Additional Experience } \\
\text { of the Proposer }\end{array}$ & $\begin{array}{c}\text { Graduate } \\
\text { Studies }\end{array}$ & $\begin{array}{c}\text { Additional } \\
\text { Experience }\end{array}$ & $\begin{array}{c}\text { Graduate } \\
\text { Studies }\end{array}$ & $\begin{array}{c}\text { Additional } \\
\text { Experience }\end{array}$ & $\begin{array}{c}\text { Graduate } \\
\text { Studies }\end{array}$ & $\begin{array}{c}\text { Additional } \\
\text { Experience }\end{array}$ & $\begin{array}{c}\text { National } \\
\text { Industry }\end{array}$ \\
\hline Consorcio Infraestructura & 47333.44 & 100 & 5.55 & 0 & 3.01 & 40 & 2.41 & 100 \\
\hline EDICO SAS & 52696.28 & 100 & 7 & 0 & 6.52 & 40 & 14.04 & 100 \\
\hline Consorcio AMP & 25658.76 & 0 & 0 & 0 & 0 & 0 & 0 & 100 \\
\hline CONSUCON LTDA & 46331.25 & 0 & 8.5 & 0 & 3.76 & 40 & 7.73 & 100 \\
\hline Augusto Acuña Arango & 59069.64 & 100 & 5.58 & 0 & 0.96 & 0 & 1.71 & 100 \\
\hline Martin Sanchez Palma & 31923.53 & 0 & 1.2 & 0 & 1.84 & 40 & 4.36 & 100 \\
\hline
\end{tabular}

TABLE IV. NO QUALIFYING INFORMATION ON AWARDED PROPONENT'S PROCESS CM-MEN-04-2013

\begin{tabular}{|l|c|c|c|}
\hline \multicolumn{5}{|c|}{ NO QUALIFYING } \\
\hline \multicolumn{1}{|c|}{ Item\Contractor } & Consorcio Infraestructura & EDICO SAS & CONSUCON LTDA \\
\hline Previous contracts & $\$ 1,222,596,845.45$ & $\$ 1,675,211,272.80$ & $\$ 1,543,845,116.60$ \\
\hline Total Contract & $\$ 3,815,427,578.40$ & $\$ 3,629,654,788.84$ & $\$ 3,561,736,855.00$ \\
\hline Current asset & $\$ 1,638,367,204.77$ & $\$ 932,633,087.00$ & $\$ 311,291,000.00$ \\
\hline Assets & $\$ 1,981,807,780.77$ & $\$ 2,059,823,186.00$ & $\$ 850,034,000.00$ \\
\hline Current Liability & $\$ 461,156,698.98$ & $\$ 31,618,196.00$ & $\$ 28,043,000.00$ \\
\hline Liability & $\$ 1,051,748,567.69$ & $\$ 458,706,175.00$ & $\$ 193,496,000.00$ \\
\hline Estate & $\$ 930,059,213.08$ & $\$ 1,601,117,011.00$ & $\$ 656,538,000.00$ \\
\hline Liquidity & 3.55 & 29.50 & 11.10 \\
\hline Indebtedness & $53.07 \%$ & $22.27 \%$ & $22.76 \%$ \\
\hline Working Capital & $\$ 1,177,210,505.79$ & $\$ 901,014,891.00$ & $\$ 283,248,000.00$ \\
\hline
\end{tabular}

Once the AHP was developed, the results obtained are presented in Table 5.

TABLE V. COMPARISON OF RESULTS PROCESS CM-MEN-04-2013 VS. AHP

\begin{tabular}{|c|c|c|c|c|}
\hline Order & Contractor (Process) & Points (process) & Contractor (AHP) & \multirow{2}{*}{ Points (AHP) } \\
\hline 1 & EDICO SAS & 960 & EDICO SAS & 0.2247 \\
\hline 2 & Consorcio Infraestructura & 960 & Augusto Acuña Arango & 0.1989 \\
\hline 3 & Consucon Limitada & 860 & Consorcio Infraestructura & 0.1898 \\
\hline 4 & Augusto Acuña Arango & 820 & Consucon Limitada & 0.1791 \\
\hline 5 & Martin Sanchez Palma & 780 & Martin Sanchez Palma & 0.1210 \\
\hline 6 & Consorcio AMP & 500 & Consorcio AMP & 0.0865 \\
\hline
\end{tabular}

Likewise, through the irrelevant information obtained on the hiring process, a comparison between the three contractor's process and financial indices presented by these is performed (Fig. 3). This comparison makes it possible to consider the final results of the execution of contracts (Table
6). It is important to clarify that no respective liquidation proceedings were found, so it is assumed that the processes were completed because the dates were expired and there were no new moves in this process. 
Proc. of the Third Intl. Conf. Advances in Civil, Structural and Mechanical Engineering- CSM 2015

Copyright (C) Institute of Research Engineers and Doctors, USA .All rights reserved.

ISBN: 978-1-63248-062-0 doi: 10.15224/ 978-1-63248-062-0-67

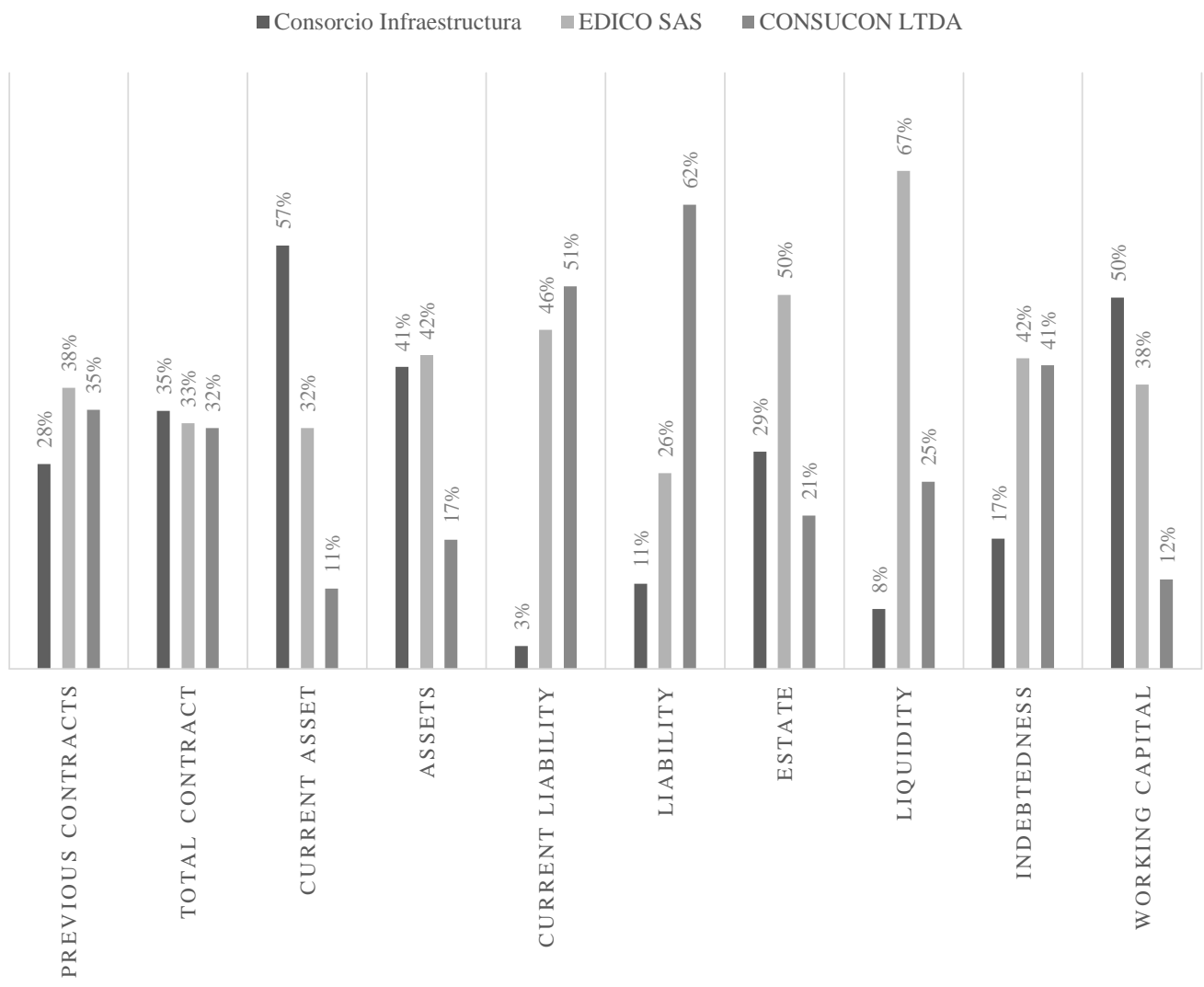

Figure 3. Comparison of qualifying information on awarded proponent's process CM-MEN-04-2013.

TABLE VI. FINAL RESULTS PROCESS CM-MEN-04-2013

\begin{tabular}{|c|c|c|c|}
\hline & $\begin{array}{c}\text { Consorcio Infraestructura } \\
\mathbf{6 8 0} \text { de 2013 }\end{array}$ & $\begin{array}{c}\text { EDICO SAS } \\
\mathbf{6 7 9} \text { de 2013 }\end{array}$ & $\begin{array}{c}\text { Consucon Limitada } \\
\mathbf{6 7 8} \text { de 2013 }\end{array}$ \\
\hline Start Date & $30 / 08 / 2013$ & $30 / 08 / 2013$ & $30 / 08 / 2013$ \\
\hline Date of Completion & $29 / 12 / 2013$ & $29 / 12 / 2013$ & $29 / 12 / 2013$ \\
\hline Duration [days] & 122 & 122 & 122 \\
\hline Total Budget & $\$ 545,155,920.00$ & $\$ 551,153,366.00$ & $\$ 519,775,816.00$ \\
\hline Real Date of Completion & $30 / 09 / 2014$ & $30 / 09 / 2014$ & $31 / 10 / 2014$ \\
\hline extensions [days] & 275 & 275 & 306 \\
\hline Additions & 0 & 0 & 0 \\
\hline Arrears & $225 \%$ & $225 \%$ & $251 \%$ \\
\hline Overruns & $0 \%$ & $0 \%$ & $0 \%$ \\
\hline
\end{tabular}

\section{Discussion of Results}

In the present research, a case study is analyzed to generate comparisons in terms of traditional recruitment processes and by applying the AHP, finding differences between the results of the recruitment process and results from AHP.
The major cause of this difference is the weight assigned to the additional criterion of the specific experience of the proposer. This criterion is $50 \%$ by weight of the entire process and it is the criterion on which the proponent Augusto Acuña Arango has a large advantage over the other contractors. This advantage is evidenced by the AHP, since this allows him to excel; otherwise with the traditional qualification process, 
despite standing out among the proponents, he gets the same rating as other bidders.

An important aspect is that the documents required by the contractors for qualifying requirements were not taken into account when the bidder's qualifications were built (Fig. 3). In other words, this information is not used for comparison between the proponents.

On the other hand, the importance given to the staff of contractors, specifically the importance given to the Project Manager, is very relevant. This factor is curious whenever the contract is for the realization of designs, where it could be understood that designers should have more weight in qualifying.

As results of the process, the three contractors who were awarded contracts had a similar execution. Overruns were not presented, but delays exceeded $200 \%$ of delivery in all cases (Table 6). However, the worst performance was submitted by Consucon Limited, which, from the non-scoring data, is the contractor submitting less positive factors in comparison with others. Similarly, Consucon Limited was the contractor removed by the AHP, for the reason that the contractor would have a lower probability of satisfactory execution for process development.

\section{vII. Conclusions}

It is observed through the results that all the contracts that were studied in this investigation ended with delays of more than $200 \%$. Therefore, it is concluded that the requirements requested of the contractors fail to meet the objective of ensuring good performance, so all the documentation and requested variables should be reviewed in order to improve the process. For this reason, there should be a reliance upon the existence of documents that, while not taken into consideration for scoring, are delivered by the contractors.

However, it was observed that the AHP managed to predict correctly which of the performers might be more likely to fail in the development of contracts. For this reason, it is advisable to start using the AHP as a measure in contracting processes.

Unfortunately, to the best of the author's knowledge, there is no evidence of the implementation of these processes in the field of public sector construction around the world. However, this may be an opportunity to become pioneers in a system that aims to give people the tools to make their work seen as properly qualified and accurate by the authorities responsible for monitoring compliance with laws, as well as by the general population.

Although the AHP enjoys great prestige and academic and scientific recognition worldwide, it must be evaluated through scientific research and additional practices in order to ensure its correct functionality in the selection of bidders in the public sector.

For this reason, it is necessary to continue research into the use of the AHP in the field of construction, recommending the implementation of a pilot plan to begin the pursuit of real data, which will focus on testing the potential benefits of the application of methods from Decision Theory.

\section{Recommendations}

The factor that presents the greatest number of drawbacks around public procurement is the perceived lack of transparency in the procurement process. However, it is possible to show that the AHP process generally arrives at the same results established by using different recruitment processes, demonstrating the honest approach followed in awarding the contracts that were the subject of the case study.

However, in order to generate greater confidence in the applicability of transparent processes, the AHP is a useful and effective tool to select a contractor with a guarantee of objectivity. Despite this, it is necessary to go further in demonstrating the feasibility of such tools in government institutions in Colombia.

Initially, the possible implementation of the AHP as a tool to evaluate different processes in the Colombian state can present several problems. The first problem is with the nontenure staff who are trained to structure and evaluate projects via the AHP. On the other hand, it is possible to observe the reluctance of the various directives to implement a new process that takes an existing operation and aims for final acceptance and understanding by the various proponents of the specific process.

Delving a bit further on the question asked, the use of unqualified personnel to structure and evaluate recruitment projects through the Analytic Hierarchy Process could lead to a misunderstanding of the process itself and thus make an erroneous selection between alternatives. For this reason and in order to generate correct results, a focus is required on providing training for persons in charge to give them a thorough understanding of the AHP.

Continuing with the above, this type of uncertainty about a new tool could generate distrust of the people responsible for accepting or rejecting the implementation of the tool. For this reason, in order to build trust, it is necessary to generate a progressive implementation process. Likewise, understanding and acceptance by the participants in the recruitment process will be vital, because they will seek to make a profit from the different processes awarded.

Once these processes are met, it is necessary to continue with an additional one that seeks acceptance of the improvements provided by the AHP among the general population. As stated at the beginning, one of the main problems of recruitment in Colombia is the sense of a lack of transparency in the process. However, to end these perceptions, the new deployment model needs to enjoy the acceptance of people interested in the subject, and it can then become a benchmark of good practice for society in general. 


\section{Ix. References}

[1] Abdelrahman, M., Zayed, T., \& Elyamany, A. "Best Value Model Based on Project Specific Characteristics." Journal of Construction Engineering and Management, 2008, pp. 179-188.

[2] Ando, R. "Evaluation of Priority to Construct Trunk Roads around a Local City." In Applications of Advanced Technologies in Transportation Engineering, edited by Kumares C. Sinha, T. F. Fwa, Ruey L. Cheu, and Der Horng Lee. Beijing, 2004, pp.626-630.

[3] Casañ Perez, A., Ponz Tienda, J. L., \& Bustos Chocomeli, O. H. La Decision Multicriterio; Aplicacion en la seleccion de ofertas competitivas en edificacion. Valencia, 2013.

[4] Chen, H., \& Qin, T. "Studies on Risk Management of the Urban Infrastructure Projects Based on the BOT Financing Model." In Performance Modeling and Evaluation of Pavement Systems and Materials: Selected Papers from the 2009 GeoHunan International Conference, edited by Halil Ceylan, Kasthurirangan Gopalakrishnan, Xueyan Liu, and Likui Huang. Changsha, 2009, pp. 39-46.

[5] Chen, T. T., \& Hsu, Y. T. "Study on Highway Construction Leads to the National Compensation." In Application of Nanotechnology in Pavements, Geological Disasters, and Foundation Settlement Control Technology, edited by Dharamveer Singh, Lubinda F. Walubita, Jeongho Oh, and Kun Li. Yichang, 2014, pp. 46-53.

[6] Chen, X. Y., Yang, X. K., \& Xu, Z. "Location Configuration Design of New Park and Ride Facilities in Beijing, China." CICTP 2012: Multimodal Transportation Systems: Convenient, Safe, Cost-Effective, Efficient, edited by Clara Fang, Heng Wei, Yunpeng Wang, and Jun Zhang. Beijing, 2012, pp. 11-22.

[7] Cheng, H., \& Yang, X. K. "A Comprehensive Evaluation Model for Earthquake Emergency Shelter." In Sustainable Transportation Systems: Plan, Design, Build, Manage and Maintain, edited by Yong Bai, Wei Shou, Virgil Ping, L. David Shen, and Xiaohu Chen. Chongqing, 2012, pp. 412-422.

[8] Herath, G. "Multi-Criteria Decision Making in Water Resources Planning: What does the Evidence Show". Intellectbase International Consortium.

[9] Jiang, X., Lei, M., Li, Y., \& Dai, J. "National Scale Risk Assessment of Sinkhole Hazard in China." In Sinkholes and the Engineering and Environmental Impacts of Karst, edited by Barry F. Beck. San Antonio, 2005, pp. 649-658.

[10] Min, H. "Location Analysis of International Consolidation Terminals Using the Analytic Hierarchy Process." Journal of Business Logistics, 1994, pp. 25-44.

[11] Qin, Y. “Appraisal of Regional Logistics Development in China.” In ICLEM 2010: Logistics for Sustained Economic Development: Infrastructure, Information, Integration, edited by Jin Zhang, Ling Xu, Xiaoqiang Zhang, Ping Yi, and Ming Jian. Chengdu, 2010, pp. 632-636.

[12] Saaty, T. Optimization by the Analytic Hierarchy Process. Philadelphia, 1979.

[13] Valdes Vasquez, R., \& Klotz, L. E. "Social Sustainability Considerations during Planning and Design: Framework of Processes for Construction Projects." Journal of Construction Engineering and Management, 2013, pp. 80-89.

[14] Vallejo, J. A., Ponz, J. L., \& Alzate, G. A. "Evaluación a los Procedimientos de Selección de Oferentes en Procesos de Contratación del Sector Público Enfocados a la Construcción (Consultoría) por medio de la Decisión Multicriterio", 2014.

[15] Xue, L., Zhang, L., \& Yang, Y. "The Analytic Hierarchy Process Based Optimal Forwarder Selection in Multi Hop Broadcasting Scheme for Vehicular Safety." In CICTP 2014: Safe, Smart, and Sustainable Multimodal Transportation Systems, edited by Jianming Ma, Yafeng Yi, Helai Huang, and Difu Pan. Changsha, 2014, pp. 640-648.

[16] Xue, Y., \& Liu, R. "Evaluation of Psychological Rescue Capabilities of Small Towns Based on FAHP.” In ICCREM 2014: Smart Construction and Management in the Context of New Technology, edited by Yaowu Wang, Haowen Ye, Geofrey Q. P. Shen, and Yong Bai. Kunming, 2014, pp. 1694-1702.
[17] Yuan, J., Guang, M., Wang, X., Li, Q., \& Skibniewski, M. J. "Quantitative SWOT Analysis of Public Housing Delivery by Public Private Partnerships in China Based on the Perspective of the Public Sector.” Journal of Management in Engineering, 2012, pp. 407-420.

About Author (s):

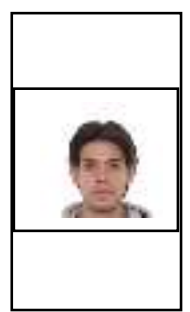

MSc. Jose Agustin Vallejo

BSc. Civil Engineering

Doctoral Student Universidad de los Andes

Doctoral Student Universitat Politècnica de València 